\title{
ENCOUNTER COMPLICATIONS DURING TREATMENT FOR RADIATION-ULCER: FIVE YEARS IN EXPERIENCE
}

\author{
Hoang Thanh Tuan, Vu Quang Vinh, Tran Van Anh, \\ Tong Thanh Hai, Do Trung Quyet \\ Le Huu Trac National Burn Hospital
}

\begin{abstract}
SUMMARY
Complications of radiation-induced ulcers are one of the most challenging situations a reconstructive surgeon can encounter. In that case, finding an optimal solution to cover the defect is not easy. In this paper, we presented our experience in dealing with such drastic ulcers, dividing them into 4 groups.

+ Group A: Exposed carotid artery.

+ Group B: Exposed axillary artery.

+ Group C: Exposed pleura and pericardium.

+ Group D: Exposed tracheal stenosis.

All patients underwent appropriate reconstructive surgery methods and recovered well with acceptable functional and cosmetic outcomes.
\end{abstract}

Keywords: Radiation therapy, radiation-induced ulcers, reconstructive surgery, TRAM flap, LDM flap.

\section{INTRODUCTION}

Radiation therapy (RT) has a substantial impact on the treatment of cancer. However, its side effect was irreversible [1]. Nearly 60 percent of surgical patients underwent the complication of RT [2]. It included: Skin atrophy, soft tissue fibrosis, desquamation, epithelial ulceration, fistula formation, and major vessel rupture $[2,3]$. Ulcer, the most frequent damage of local irradiation, was the late advert effect of radiation [4]. Wide debridement and reconstructive method

Corresponding author: Hoang Thanh Tuan, Le Huu Trac National Burn Hospital Email: tuanht.vb@gmail.com Ngày nhận bài: 05/1/2022; Ngày nhận xét: 15/1/2022; Ngày duyệt bài: 22/1/2022 https://doi.org/10.54804/yhthvb.6.2021.90 were applied to improve the quality of the patients' life [5, 6].

During the progress of reconstruction of the procedure, several previous studies indicated severe complications, such as exposure to the carotid artery, tracheal stenosis, pleura, and pericardium in the chest [7]. It makes much confusion for the reconstructive surgeons. This study sought to show our experience in controlling the complication during treatment for radiation induce-ulcer.

\section{METHOD}

From 2015 to 2019 , among the patients admitted to the Plastic, Reconstructive, and Regenerative Centre of the Le Huu Trac National Burn Hospital, we recruited nine patients to this study who had severe complications. 
After giving informed consent, we examined the ulcer and chose the best surgery method for each patient. The dimension of the wound was noted. During the operation, we widely debrided the ulcer, designed the flap, and immediately cover the defective side. Type of flaps included: Local, pedicle, and free flap. We also recorded the length of stay of all the patients. There was no contraindicated for operation in these patients.

\section{RESULT}

The male gender takes $40 \%$; the median age was 63 years (range from 49 to 77). Breast cancer and nasopharyngeal cancer were two leading causes that lead the patient to radiation therapy. The period
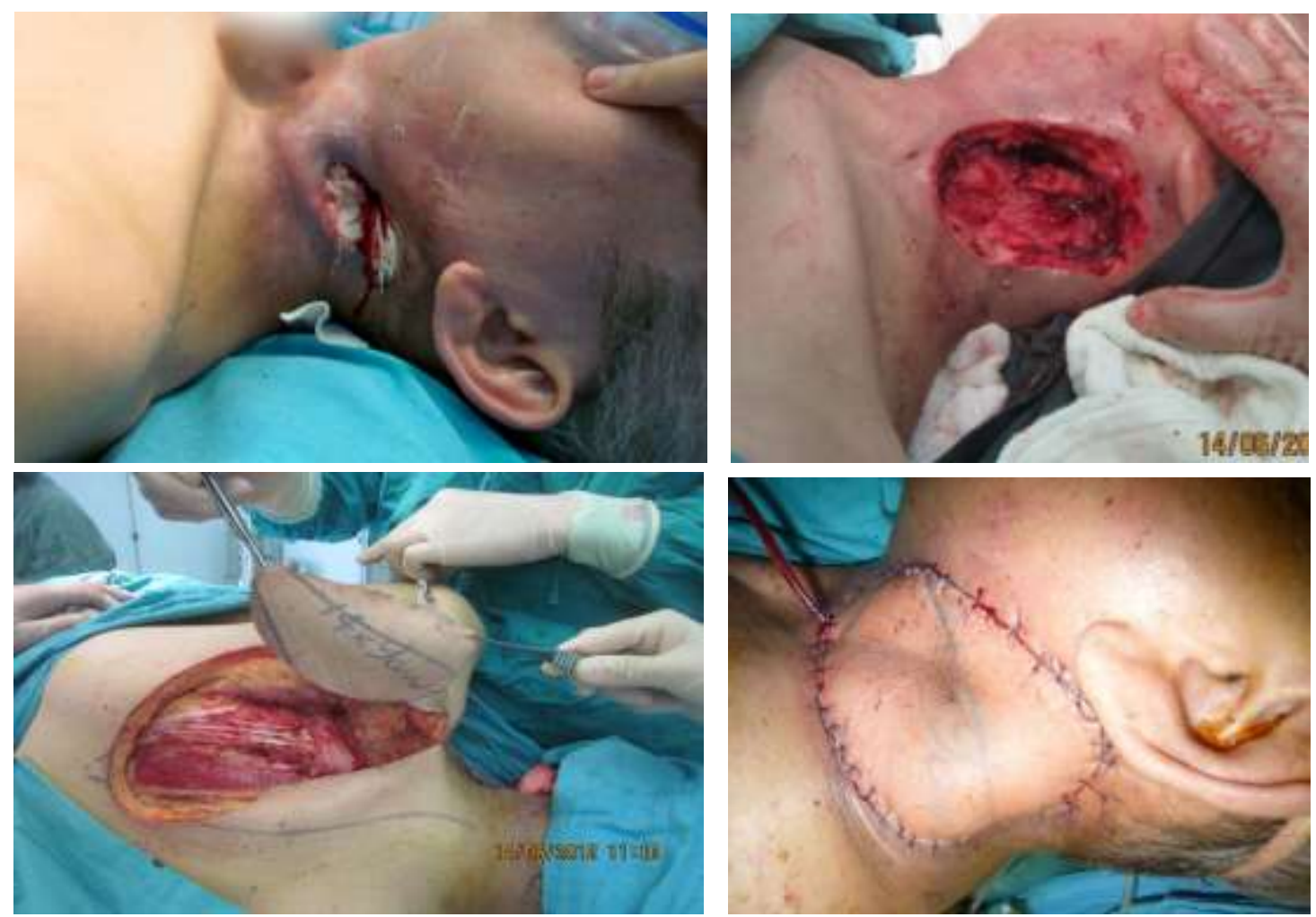

Fig. 1. This 49-year-old male had a left ulcer in the neck one year after radiation therapy due to tongue cancer (upper, left). After widely debriding the ulcer, the carotid artery was exposed (upper, right). He had immediately reconstructive surgery by using a TM flap on the same side of the wound (lower, left) and the result right after the operation (lower, right). from finishing radiation therapy to appearing radiation induce ulcer was from 1 to 30 years.

During the operation, the encounter complications in all nine patients were divided into four categories:

- Group A: Exposure the carotid artery

In the first three patients with a nasopharyngeal cancer history, the irradiation side was on the right side of the patient's neck. After removing the ulcer, the carotid artery was exposed and easily damaged. Facial lata was harvested from the right thigh to cover the carotid artery. Finally, the Trapezius musculocutaneous (TM) flap played a pivotal role in covering the artery (Fig. 1). 
- Group B: Exposure the axillary artery

The next 2 cases in Table 1 underwent the axillary artery during the procedure takes place. Perforator pedicle propeller flap was designed to cover the wound after wide resection of the ulcer (Fig. 2).

Table 1. The summary of patients' characteristics and demographic data

\begin{tabular}{|c|c|c|c|c|c|c|c|c|}
\hline ID & Age & Gender & Cancer & $\begin{array}{c}\text { Time to appear } \\
\text { ulcer (year) }\end{array}$ & $\begin{array}{c}\text { Dimention } \\
(\mathbf{c m})\end{array}$ & Complication & $\begin{array}{c}\text { Type of } \\
\text { flaps }\end{array}$ & Los \\
\hline 1 & 63 & Male & Nasopharyngeal & 6 & $6 \times 10$ & Carotid artery & TM & 120 \\
\hline 2 & 63 & Male & Nasopharyngeal & 8 & $5 \times 8$ & Carotid artery & TM & 15 \\
\hline 3 & 49 & Male & Tounge & 1 & $5 \times 6$ & Carotid artery & Free & 92 \\
\hline 4 & 57 & Female & Breast & 10 & $5 \times 6$ & Axilary artery & LDM & 30 \\
\hline 5 & 59 & Female & Breast & 12 & $4 \times 6$ & Axilary artery & PPP & 33 \\
\hline 6 & 63 & Female & Breast & 10 & $14 \times 16$ & Pleura & LDM & 29 \\
\hline 7 & 59 & Female & Breast & 10 & $10 \times 12$ & Pericardium & TRAM & 119 \\
\hline 8 & 77 & Female & Breast & 30 & $5 \times 6$ & Pleura & LDM & 47 \\
\hline 9 & 70 & Male & Thyroid & 5 & $3 \times 3$ & Treachal & Local & 19 \\
\hline
\end{tabular}

(TM: Trapezius musculocutaneous; LDM: Latissimus Dorsi Myocutaneous; PPP: Perforator pedicle propeller).
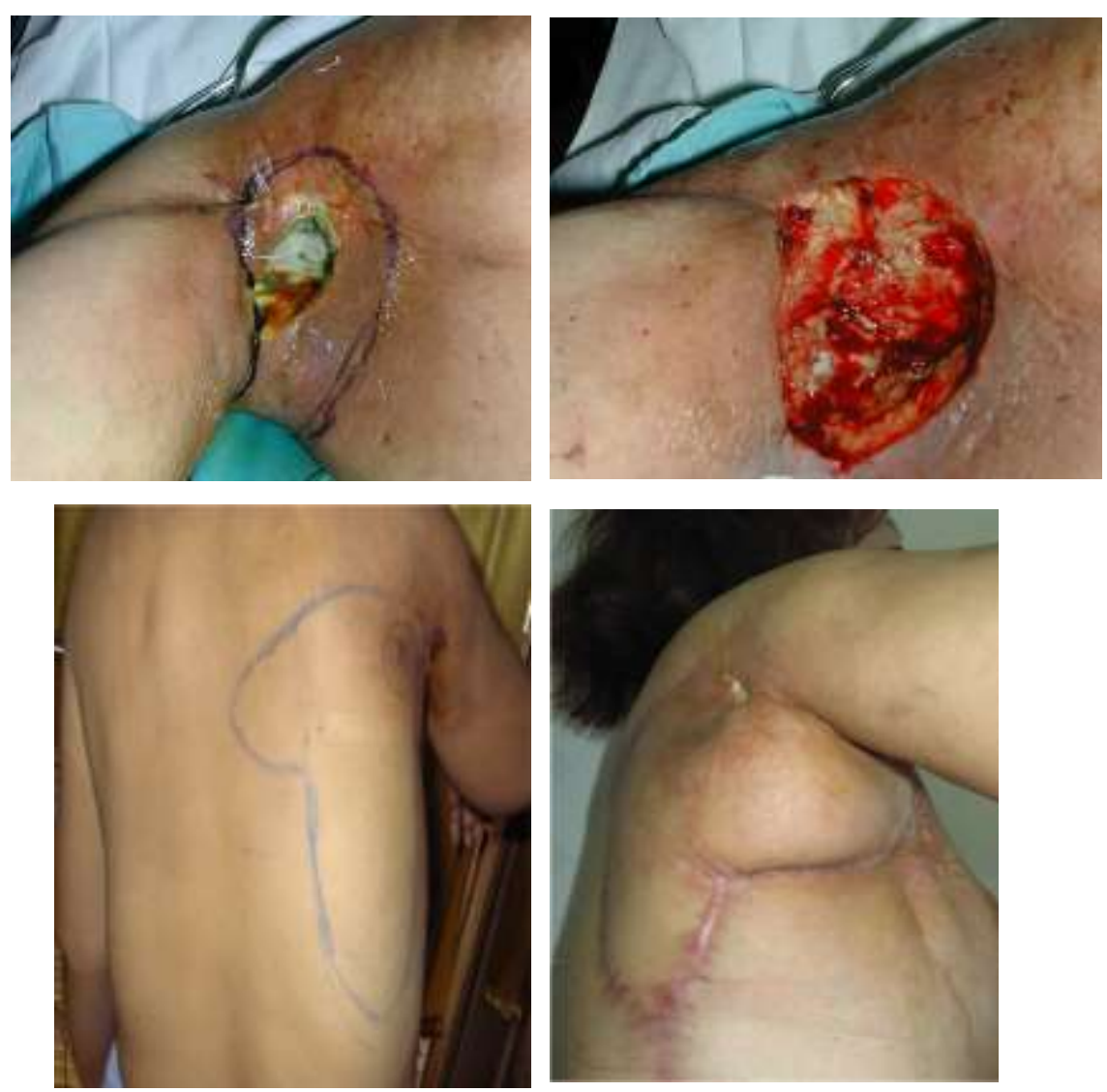

Fig. 2. This 59-years-old female presented with a breast cancer history, and RT alone appeared the ulcer after 12 years (upper, left). After excision, the axillary artery was below the wound bed (upper, right). A PPP flap based on the circumflex humeral artery was designed and immediately covered the wound (lower, left, and right). 
- Group C: Exposure the pleura and pericardium

As a consequence of breast cancer, the ulcer was seen on the chest (cases 6 to 8). We removed a part of the concerned rib during remove necrosis of the wound so that exposure the pleura and pericardium. Immediately, Perforator Pedicle Propeller and TRAM flap covered this region (Fig. 3 and 4).
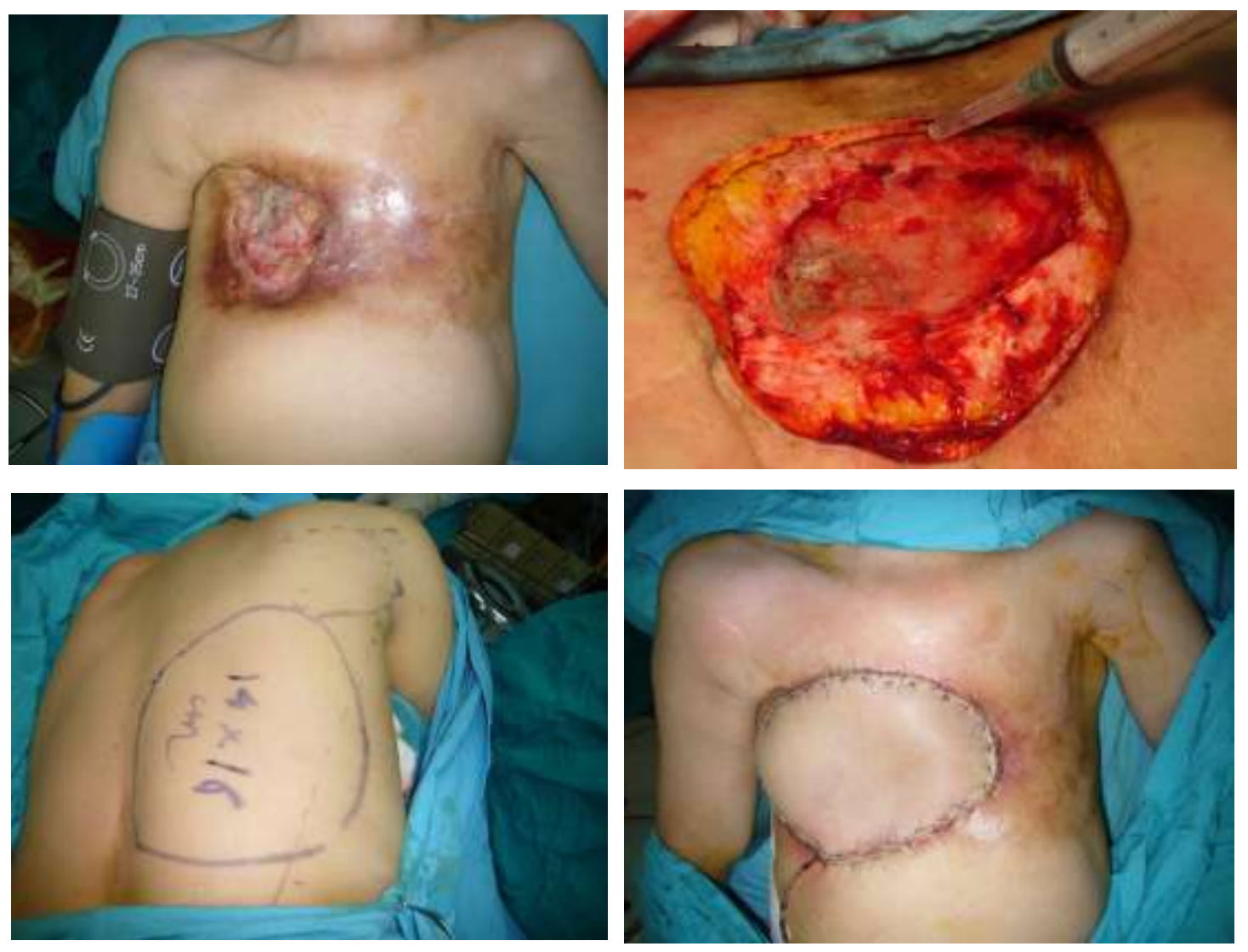

Fig. 3. This 63-years-old female presented with breast cancer history and RT alone, living with the wound for nearly ten years (upper, left). After excision and removing the rib, the pleura was seen at the wound bed (upper, right). LDM flap was applied and immediately covered the wound (lower, left, and right) 

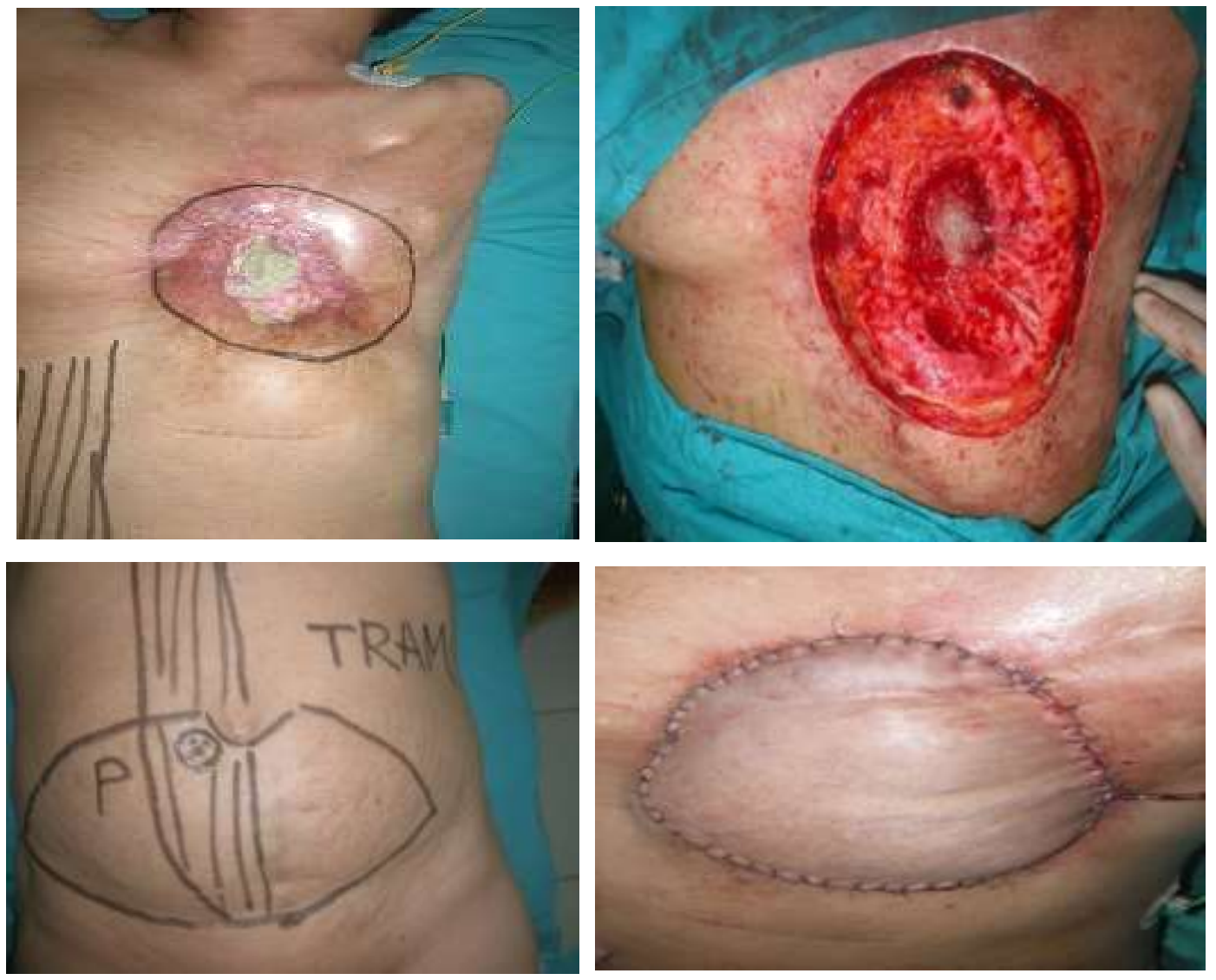

Fig.4. This 59-years-old female had a breast cancer history and RT alone, living without ulcer treatment for ten years (upper, left). After excision and removing the rib, the pericardium was exposed (upper, right). TRAM flap was applied and immediately covered the wound (lower, left, and right).

- Group D: Tracheal stenosis

In one particular case with a thyroid cancer history, the MRI illustrated the tracheal stenosis due to its scar after irradiation. We also noted a small ulcer in the neck. We decided to use an implant to reshape the tracheal and apply a local flap to cover the wound (Fig. 5). 

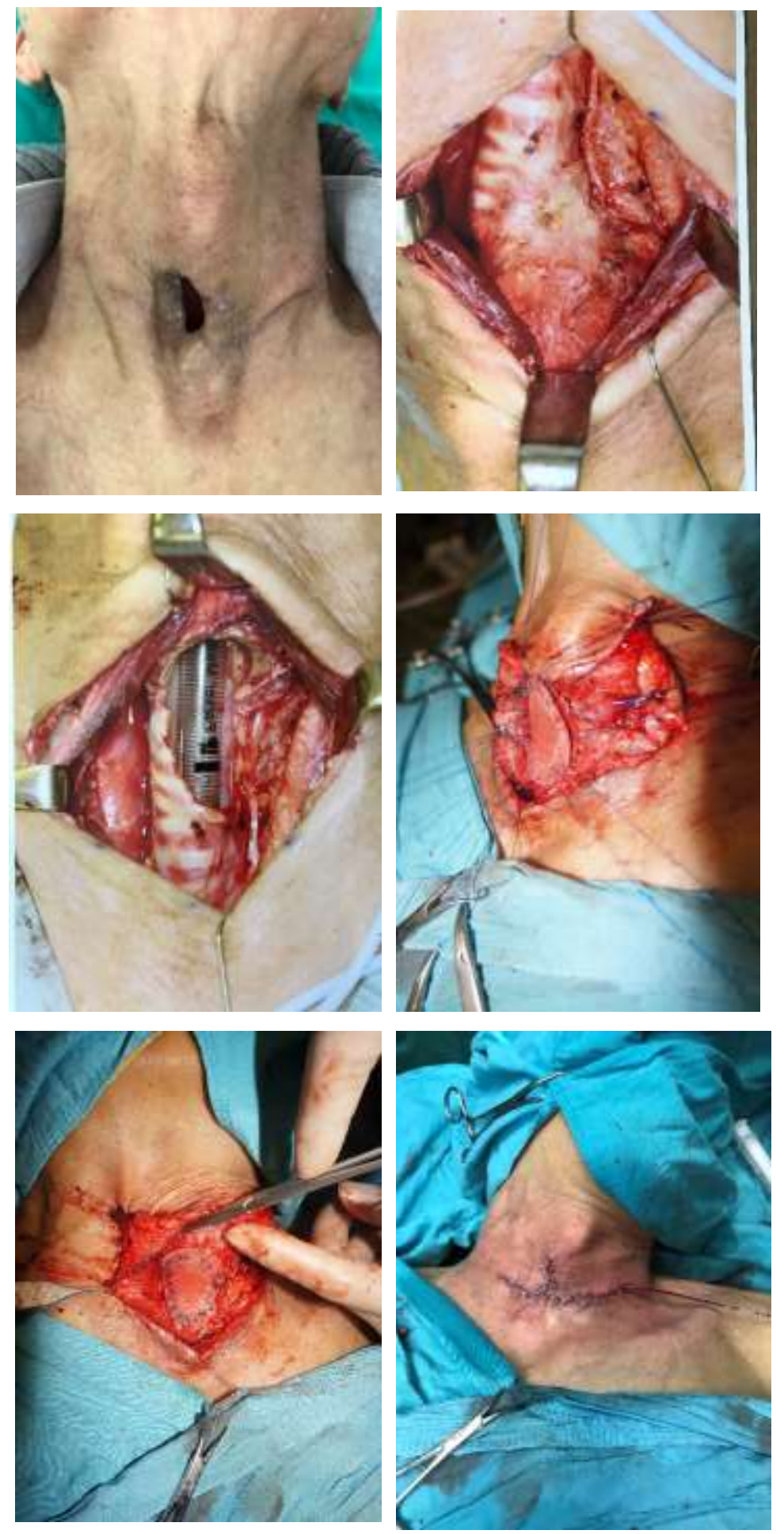

Fig. 5. This 70-year-old case with a thyroid cancer history appeared the ulcer after RT (upper, left), the scar in the trachea makes this man hard to talk (upper right). We decided to use an implant material (Medpor) to reshape the trachea (lower, left) and apply a local flap to cover the wound (lower right). 


\section{DISCUSSION}

The consequences of irradiation for cancer treatment were noted in many studies before. RT seriously affected the microvascular and vessels that lead to the local ulcer. Moreover, this wound could not heal by itself. Local affected skin led to the ulcer-induced and embarrassment to the surgeon's doctors. Encountered complications during operation may contribute to the method of reconstructive surgery. This study showed our experience in controlling this daunting task in the management of radiation ulcers.

Local RT alone was the first choice for head and neck cancers. The intensive radiation protocol was applied to the region containing some vessels, including carotid arteries, to achieve the goal [8]. Once this big artery was seen after removing the ulcer's fibrosis tissue, the reconstructive flap should be applied whether this artery is damaged or not. In this study, the carotid artery was covered by a TM flap, which was widely used in head and neck reconstruction $[9,10]$.

In limited-resource settings where lack of technique and microvascular equipment, choosing a TM flap was the most appropriate. A patient presented with stenosis tracheal below the ulcer in the anterior neck. The implant (Medpor) was the material for reconstructing the tracheal (Fig.5). The result showed too surprise. The patient can talk fluently after one month.

Ulcer in the armpit often left severe complications [7]. Due to breast cancer, the axillary artery was vulnerable after $\mathrm{RT}$. We also found the same circumstance with the neck when debrided the ulcer in the armpit region. Besides, it limited shoulder movement and inhibited daily activities. As a result, the perforator pedicle propeller flap showed its advantages in cover and improved joint function.

TRAM and LDM flaps had strong effectiveness in reshaping the breast after irradiation. Two above flaps have long been captured in breast reconstruction [11, 12]. Our study used them to cover the defective side, where may contain a little necrotic in the wound bed after removing the ulcer, without implant material. Complete wound healing had priority over aesthetic purposes because all the patients have suffered from these ulcers for a long time. Also, LDM and TRAM flaps were known as a well-revascularization. It can bring nutrients and antibiotic that makes the wound heals faster.

\section{CONCLUSION}

Irradiation ulcer was one of the most burdensome consequences of radiation therapy due to non-healing, so we need to apply a radical treatment like reconstruction procedure. The reconstructive flap shows its advantages in solving the ulcer and can manage the encountered complication with good results. In the future, the combination of therapeutic and reconstructive doctors may help cancer patients have a better life after radiation treatment. 


\section{REFERENCES}

1. Wei, J., Meng, L., Hou, X., et al. Radiationinduced skin reactions: mechanism and treatment. Cancer management and research 2019;11:167-177.

2. Haubner, E. O., Fabian Pohl. Wound healing after radiation therapy: Review of the literature. Radiation oncology 2012:9.

3. Fujioka, M. Surgical Reconstruction of Radiation Injuries. Advances in wound care 2014;3:25-37.

4. Bolderston, A., Lloyd, N. S., Wong, R. K., Holden, L., Robb-Blenderman, L., Supportive Care Guidelines Group of Cancer Care Ontario Program in Evidence-Based, C. The prevention and management of acute skin reactions related to radiation therapy: a systematic review and practice guideline. Supportive care in cancer: official journal of the Multinational Association of Supportive Care in Cancer 2006;14:802-817.

5. Felice, P. A., Nelson, N. S., Page, E. E., et al. Amifostine reduces radiation-induced complications in a murine model of expanderbased breast reconstruction. Plastic and reconstructive surgery 2014;134:551e-560e.

6. Seungtaek Choi, D. L. S., Greg Farwell, Mary Austin-Seymour, Neal Futran. Radiation Therapy Does Not Impact Local Complication Rates After Free Flap Reconstruction for Head and Neck Cancer. Arch Otolaryngol Head Neck Surg 2004;130:5.
7. Ma, X., Jin, Z., Li, G., Yang, W. Classification of chronic radiation-induced ulcers in the chest wall after surgery in breast cancers. Radiation oncology 2017;12:135.

8. Rose-Ped, A. M., Bellm, L. A., Epstein, J. B., Trotti, A., Gwede, C., Fuchs, H. J. Complications of radiation therapy for head and neck cancers. The patient's perspective. Cancer nursing 2002;25:461-467; quiz 468-469.

9. Yang, H. J., Lee, D. H., Kim, Y. W., Lee, S. G., Cheon, Y. W. The Trapezius Muscle Flap: A Viable Alternative for Posterior Scalp and Neck Reconstruction. Archives of plastic surgery 2016;43:529-535.

10. Motamed, S., Davami, B., Daghagheleh, H. Trapezius musculocutaneous flap in severe shoulder and neck burn. Burns: Journal of the International Society for Burn Injuries 2004;30:476-480.

11. Sood, R., Easow, J. M., Konopka, G., Panthaki, Z. J. Latissimus Dorsi Flap in Breast Reconstruction: Recent Innovations in the Workhorse Flap. Cancer control: Journal of the Moffitt Cancer Center 2018;25:1073274817744638.

12. Galen Perdikis, S. K., George Collis, Dustin Eck. Latissimus Dorsi Myocutaneous Flap for Breast Reconstruction: Bad Rap or Good Flap? Open Access Journal of Plastic Surgery 2011;11:6. 